\title{
Editorial
}

\section{Valorization of Agroforest Crops for Biomass Utilization}

There is a growing need to consider alternative agricultural strategies that move an agricultural industry focused on food production to one that also supplies the needs of other industrial sectors, such as paper, textiles, biofuels or added-value chemicals, in the context of the so-called lignocellulose biorefinery. Biorefineries use renewable raw materials to produce energy together with a wide range of everyday commodities in an economic manner. Decreasing our dependency on fossil fuel reserves and boosting rural development are important goals of modern society. Biorefineries are therefore seen as a very promising route to meeting our aims for sustained prosperity and preserving the environment. Renewable sources of energy and products are required for sustainable development of our society in the near future. Plant biomass is the main source of renewable materials in Earth and represents a potential source of renewable energy and biobased products. Biomass is available in high amounts at very low cost (as forest, agricultural or industrial lignocellulosic wastes and cultures) and could be a widely available and inexpensive source for biofuels and bioproducts in the near future.

This special issue of The Open Agriculture Journal is devoted to the "Valorization of agroforest crops for biomass utilization" and provides a comprehensive description of the current state-of-the-art in the whole fields of lignocellulose biorefineries, including studies on different feedstocks (plant biomass, agro-industrial residues, energy crops or new industrial crops), technologies for biomass deconstruction and fractionation (i.e. alkaline pulping, organosolv fractionation), and products (i.e. biofuels, composite building materials, lignin, paper pulp and other industrial products).

Different papers by internationally recognized experts have been collected for this special issue and report various aspects of biomass utilization and valorization. Among them, the paper by Díaz et al. evaluates different fast-growing species (paulownia, tagasaste, giant reed, leucaena and sesbania) according to their biomass productivity, chemical composition and the chemical characteristics of the liquids obtained after an autohydrolysis treatment. The study confirms the feasibility of the nonisothermal autohydrolysis treatment process for the selected species to yield sugar oligomers and hemicellulosic sugar. The paper by Marques et al., on the other hand, reported the detailed chemical composition of several non-woody plant fibers (bast fibers from flax, hemp, kenaf, jute; leaf fibers from sisal, abaca and curaua; and giant reed), which are used as raw materials for pulp and papermaking, with especial emphasis in the chemistry of lipids and lignin and their fate during alkaline pulping. This study offers valuable information that will lead to a better industrial utilization of these non-woody plant species of high socioeconomic interest. Likewise, the paper by Villaverde et al. provided a review of the chemistry of another interesting crop, Miscanthus $x$ giganteus, as a source of biobased products (i.e. paper pulp) through organosolv fractionation. Organosolv processes have demonstrated their effectiveness as fractionation treatments, therefore special emphasis was placed by the authors on these systems and, in particular, in those using carboxylic acids, such as the Acetosolv, Formosolv and Milox processes. Similarly, the paper by Gullón et al. provided an excellent review of selected process alternatives for biomass refining. Special attention was devoted to biorefinery schemes dealing with the fractionation of lignocellulosic raw materials by chemical treatments. The potential of hydrothermal treatments as the first stage of future biorefineries is discussed. Special attention was also paid to the low-volume, high-added value products that can be solubilized by this type of technology. In the same way, the paper by da Silva and Curvelo reported the acetone-water delignification of Eucalyptus urograndis, a process that also fits perfectly with the biomass biorefinery approach, and obtained high selectivity at the beginning of the pulping process. On the other hand, agricultural residues, which are usually disposed, have major components (cellulose, hemicellulose and lignin) that can also be exploited for production of bioenergy or bioproducts. In this sense, the paper by Jiménez and Rodríguez studied the valorization of agricultural residues by fractionation of their components. The authors review the different possibilities of biomass fractionation by hydrothermal treatments as well as by organosolv delignification.

Alternative and novel uses of biomass products are also reported in this special issue. Although an excellent bio-fuel, however, new uses of lignin in more high-value-added products might be more attractive and profitable. Thus, the paper by Gellerstedt et al. focused on the production of carbon fibers from lignin into the wood-based biorefinery concept. Lignin-based carbon fiber is the most value-added product from a wood-based biorefinery. The replacement of construction steel in cars and trucks with a much lighter carbon fiber-based composite will ultimately result in more fuel-efficient vehicles. Various attempts to make carbon fiber from lignins are discussed in this interesting paper. Finally, the paper by Tiilikkala et al. also reports a novel use of another biomass product, wood pyrolysis liquids (so-called wood vinegar), as biocide and plant protection product. Wood vinegar and other slow pyrolysis liquids are produced as a by-product of charcoal production. The aim of this review was to clarify the potential of slow pyrolysis liquids in agricultural use, in particular, in pesticide applications. The main challenges in developing novel bio control technologies are discussed in this paper and the barriers in the commercialization of biological control agents are revealed.

In conclusion, all the studies reported in the papers presented in this special issue are intended to get a wider and more rational use of agro-forest resources as is the cultivated plant biomass used as raw material for the manufacturing of bio-fuels 
and bio-products in the context of the biorefinery approach. As the Guest Editor of this special issue, I wish to thank all the contributing authors and reviewers for their efforts to put forth this collection of papers, that I am sure will be of high interest for the readers of The Open Agriculture Journal.

José C. del Río

(Guest Editor)

Department of Plant Biotechnology

Institute of Natural Resources and Agrobiology of Seville (IRNAS-CSIC)

Seville

Spain

E-mail: delrio@irnase.csic.es

(C) José C. del Río; Licensee Bentham Open.

This is an open access article licensed under the terms of the Creative Commons Attribution Non-Commercial License (http: //creativecommons.org/licenses/by$\mathrm{nc} / 3.0 /$ ) which permits unrestricted, non-commercial use, distribution and reproduction in any medium, provided the work is properly cited. 